\title{
Top 10 drugs
}

These tables show the top 10 subsidised drugs in 2006-07. The tables do not include private prescriptions.

Table 1

Top 10 drugs supplied by DDD*/1000 pop/day ${ }^{\dagger}$

\begin{tabular}{ll}
\hline Drug & PBS/RPBS $^{\ddagger}$ \\
\hline 1. atorvastatin & 131.799 \\
2. simvastatin & 58.072 \\
3. ramipril & 30.451 \\
4. perindopril & 21.681 \\
5. aspirin & 18.01 \\
6. omeprazole & 17.996 \\
7. frusemide & 17.984 \\
8. irbesartan & 17.28 \\
9. salbutamol & 17.116 \\
10. esomeprazole & 16.802 \\
\hline
\end{tabular}

\section{Table 2}

\section{Top 10 drugs by prescription counts ${ }^{\dagger}$}

Drug PBS/RPBS ${ }^{\ddagger}$

1. atorvastatin 10000495

2. simvastatin 6231212

3. esomeprazole 4428530

4. omeprazole 3882359

5. paracetamol 3754140

6. perindopril 3633536

7. atenolol 3217151

8. irbesartan 2989359

9. pantoprazole 2922724

10. metformin hydrochloride 2822776

Table 3

Top 10 drugs by cost to Government ${ }^{\dagger}$

\begin{tabular}{lccr}
\hline Drug & $\begin{array}{c}\text { Cost to Government } \\
\text { (\$A) }\end{array}$ & $\begin{array}{c}\text { DDD/1000/day } \\
\text { PBS/RPBS }{ }^{\ddagger}\end{array}$ & $\begin{array}{c}\text { Prescriptions } \\
\text { PBS/RPBS }\end{array}$ \\
\hline 1. atorvastatin & 562234406 & 131.799 & 10000495 \\
2. simvastatin & 309227367 & 58.072 & 6231212 \\
3. clopidogrel & 179983732 & 9.219 & 2404361 \\
4. esomeprazole & 161102420 & 16.802 & 4428530 \\
5. olanzapine & 157471533 & 3.073 & 775475 \\
6. salmeterol and fluticasone & 157239113 & -5 & 2789814 \\
7. omeprazole & 114030881 & 17.996 & 3882359 \\
8. pravastatin & 93389809 & 13.537 & 1870879 \\
9. venlafaxine & 93329210 & 11.987 & 2318531 \\
10. tiotropium bromide & 91223529 & 5.289 & 1303682 \\
\hline
\end{tabular}

* The defined daily dose (DDD)/thousand population/day is a more useful measure of drug utilisation than prescription counts. It shows how many people, in every thousand Australians, are taking the standard dose of a drug every day.

† Based on date of supply

₹ PBS Pharmaceutical Benefits Scheme, RPBS Repatriation Pharmaceutical Benefits Scheme

$\S$ Combination drugs do not have a DDD allocated

Source: Drug Utilisation Sub-Committee (DUSC) Drug Utilisation Database, as at 11 October 2007. (C) Commonwealth of Australia.

\section{NPS RADAR December 2007}

Strontium ranelate: The PBS listing for the osteoporosis drug strontium ranelate has been extended to allow treatment of postmenopausal women without an existing fracture and a bone mineral density T-score $\leq-3.0$ (primary prevention). The latest issue of NPS RADAR describes the place in therapy of strontium relative to other anti-resorptive agents.

It also contains information on:
- the listing of the anticonvulsant drug topiramate as an alternative treatment for migraine prevention, for adults unable to tolerate beta blockers or pizotifen

- updated safety information for the glitazones - rosiglitazone and pioglitazone.

See the complete reviews at www.npsradar.org.au 